Editorial

\title{
Indian Journal of Plastic Surgery: A Special Issue on Hair Restoration
}

\author{
Dinesh Kadam ${ }^{1}$ \\ ${ }^{1}$ Department of Plastic and Reconstructive Surgery, A.J. Institute of \\ Medical Sciences and Research Centre, Mangalore, Karnataka, India \\ Indian J Plast Surg 2021;54:383-384.
}

Hair transplant (HT) evolution in India coincides with global trends over the last five decades. Several Indian plastic surgeons with their enormous work output, innovations, and expertise have led this progress. It is essential to mark this evolution in academic platforms and peer groups across the specialties. Keeping these objectives and providing a comprehensive update, we present this special issue on Hair Restoration with contributions from renowned authors across the globe.

Modern hair restoration surgery has evolved over the last two decades with refined techniques and innovations. Plastic surgeons have always been at the forefront of these procedures for several decades. Historically, different reconstructive techniques have been utilized to treat alopecia, such as scalp reduction, Juri's flap, Elliot's flap, etc., with limited applications. The introduction of punch graft provided a lesser invasive procedure, but outcomes were suboptimal and often unappealing. The strip harvest and follicular unit transplantation technique heralded the present era of micrografting producing exceptional results with judicial utilization of donor sites. With the utility of minimally invasive procedures such as follicular unit extraction, HT has gained wider acceptance across the globe. Mega sessions are increasingly possible with additional donor areas for body hair harvest, improved instrumentations, and efficient teamwork. The current techniques are also eminently suited for reconstructing moustache, eyebrow, cleft lip scars, and as an adjunct to gender reaffirmation procedures.

HT surgery has emerged as a major subspecialty of aesthetic surgery. Increased awareness, accessibility, and affordability have led to an exponential increase in the number of procedures. There is a heightened interest among trainees and practitioners of different specialties to learn and establish a practice. Unfortunately, unregulated centers, including beauty clinics and chains owned by nondoctors, are offering HT with surreptitious advertisements. These are ubiquitous and unethical, misleading patients.

Globally, the HT market is expanding rapidly, with a valuation of USD 8.1 billion in 2019, which is expected to reach USD 40.1 billion by 2026 . $^{1}$ The estimation is based on the business market for the procedures, hair products, drugs, service providers, and so on. With increasing androgen alopecia affecting both men and women at younger age, its psychological impact, and overwhelming exposure to the media and advertisements, the industry has the potential to grow exponentially in India as well. Further, HT is evolving, and newer technological applications such as robotic HTs, advances in graft holding solutions, the role of stem cells, etc., are promising to be the next leap of technology. ${ }^{2}$

Under these circumstances, HT surgeons must learn the techniques well, understand the science and logic, and provide optimal results, ensuring patient safety. As the new and unscrupulous players continue to emerge in the industry, the role and responsibility of our specialty become much more pertinent to safeguard the best interests of patients. Keeping this in mind, the objective of this special issue is to provide all HT surgeons with an evidence-based platform to choose and perform different procedures and understand the limitations of each. The topics range from the basic understanding of hair biology and pathology to clinical presentation, various surgical techniques, pharmacotherapy, hair cosmetics, psychological aspects, and setting up a clinic for HT. Current topics of interest, such as post-COVID hair loss, are also included.

I am thankful to Dr. Sandeep Sattur for accepting our invitation to be the Guest Editor of this issue and curating a wide range of topics from globally renowned authors. The chosen topics would help a budding plastic surgeon as well as the more established ones to gain insight into hair restoration. The authors are both from within the country and
Address for correspondence Dinesh Kadam, MS, DNB, MCh, Department of Plastic and Reconstructive Surgery, A.J. Institute of Medical Sciences and Research Centre, Mangalore575004, Karnataka, India (e-mail: drkadam@yahoo.co.in).
DOI https://doi.org/ 10.1055/s-0041-1741036. ISSN 0970-0358. (c) 2021. Association of Plastic Surgeons of India. All rights reserved. This is an open access article published by Thieme under the terms of the Creative Commons Attribution-NonDerivative-NonCommercial-License, permitting copying and reproduction so long as the original work is given appropriate credit. Contents may not be used for commercial purposes, or adapted, remixed, transformed or built upon. (https://creativecommons.org/ licenses/by-nc-nd/4.0/)

Thieme Medical and Scientific Publishers Pvt. Ltd., A-12, 2nd Floor, Sector 2, Noida-201301 UP, India 
outside, with considerable professional experience and academic credentials.

I am confident that this special issue will generate more interest among younger colleagues and residents to pursue a career in HT with solid basics, sound techniques, and safe and ethical practice to provide a holistic approach to needy patients. Lastly, I trust this endeavor will enthuse the young to pursue this specialty and become key opinion leaders in the future.
Declaration and Conflict of Interest

None.

\section{References}

1 Global Market Insights. Hair transplant market industry trends: By Sumant Ugalmugle, Rupali Swain,. published October 2020. Accessed November 24, 2021 at: https://www.gminsights.com/industry-analysis/hair-transplant-market

2 Avram MR, Watkins SA. Robotic follicular unit extraction in hair transplantation. Dermatol Surg 2014;40(12):1319-1327 